\title{
THE REORGANIZATION OF DEVELOPMENT RIGHTS AT INTER-MUNICIPAL LEVEL: DIFFERENT SCENARIOS FOR AN ALTERNATIVE LAND-USE FORECAST IN SERIANA VALLEY IN ITALY
}

\author{
L. LAZZARINI ${ }^{1} \&$ C. CHIARINI ${ }^{2}$ \\ ${ }^{1}$ Interuniversity Department of Regional and Urban Studies and Planning, Turin Polytechnic, Italy. \\ ${ }^{2}$ Milan Polytechnic, Italy.
}

\begin{abstract}
The paper deals with the issue of inter-municipal urban planning in Italy, exploring in particular the technical procedures used by inter-municipal plans to achieve the objectives established by the involved municipalities, including an effective land-use forecast. Among the planning tools, the transfer of development rights (TDR) is particularly relevant, in fiscal terms, for the form and degree of sophistication characterizing the exchange of monetary sources between local authorities, and in territorial terms, because of the effects that new settlements produce on the territory. The case study investigated by the research is the Seriana Valley, in the province of Bergamo, in the north of Italy, a territory characterized by a low degree of cooperation connoting the municipal level. The research has proposed the identification of some criteria aimed at determining the potential problematic nature of the transformation areas and the movement of the annexes development rights. The exchange of development rights among municipalities has been carried on according to different scenarios, taking into account different possibilities of political agreement between municipalities for a shared and coherent inter-municipal land-use forecast. The research has also explored the role of the so-called "Compensation Fund", a tool for collecting the monetary resources coming from the actors involved in the process, studying in particular its role in balancing the externalities produced by the new settlements.

Keywords: building rights, inter-municipal planning, land-use forecast, planning tools.
\end{abstract}

\section{INTRODUCTION}

The Seriana Valley territory represents a challenging ground on which experimenting hypothesis of inter-municipal urban planning with a particular attention to the application of the Transfer of Development Rights (TDR), which can be considered a peculiar tool of large-scale urban planning practice $[1,2]$. This is mainly due to two reasons. On one hand, the scarce level of political collaboration connoting the municipal level reveals a panorama where municipal choices regarding land-use forecast are not shared with the surrounding municipalities. Therefore, municipalities are competing for attracting real estate developers to implement urban regeneration projects. On the other hand, since the mid-20th century, this territorial field has hosted extensive processes of urbanization, particularly in the valley floor, with a dramatic loss of high-value agricultural soil. At present, Seriana Valley is a context in which the industrial divestment processes generated by the economic crisis have been generating a large amount of empty and marginal spaces for which there is not a strategy of reuse or reconversion yet. The degree of marginality connoting this territory is coloured of different nuances: large brownfields, unbuilt lots, abandoned agricultural areas are describing 
a geography of residual [3], for which small municipalities have no the financial sources to deal with. The tangible reality of this urban landscape seems to ask for a change in direction, stating a new vision for both existing dismissed spaces and new foreseen areas, according to an alternative and more sustainable land-use forecast, that could frame a common interest between municipalities to reduce soil consumptions and to deal with the new real estate conditions. The paper is organized as following: a first chapter investigates the current planning framework, underlying its weaknesses and critical factors. A second chapter examines the core of the research, the inter-municipal reorganization of land-use forecast, which has been done taking into account different scenarios of political agreement between municipalities. The last chapter focuses on a more detailed investigation of one of the three scenarios, the one expressing the highest level of cooperation between municipalities, which is considered the most advisable in terms of an efficient horizontal governance.

\section{AN ATTEMPT TO INVESTIGATE PLANNING TOOLS' DEGREE OF EFFICACY}

\subsection{Problems and incoherency at provincial level}

The planning tools survey has revealed some crucial issues about the relationship between different planning levels; it was noticed a lack of coherence in planning prescriptions between the municipal and provincial planning tools. In its "Environment and Landscape" section, the provincial plan of Bergamo [4] adopts a classification of different types of green areas that are associated with a number of requirements aimed at defining the permitted urban transformations. In particular, the regulatory system of the plan (in Italian "Norme Tecniche di Attuazione") states that "in the mainly undeveloped areas located in proximity to urban contexts, the expansion and the urban transformations oriented to the re-composition of the built fringe areas are admitted" (art. 62). Similarly, for "agricultural areas with protection and conservation aims", the plan, while identifying their borders in a map, specifies that "the perimeters of these areas are indicative and they may be subjected to modifications by the municipal planning tools" (art. 65). Finally, despite the fact that the provincial plan underlines the high naturalistic and agricultural values of the slopes of the hills and foothills, then it specifies that "these areas could be the ground of completion and building expansion interventions, provided that they will involve urban fringe areas, discontinued or marginal agricultural areas" (art. 59). Finally, the provincial plan identifies the "areas with high landscape value" where "there may be admitted interventions that provide building and planning transformations of the territory only if directed to activities necessary for the agricultural, farm tourism and agro - forestry - pastoral management". In the reality, what was noticed according to the official maps of the provincial plan, is the fact that the extension of hill and foothill zones and of the high-value agricultural areas is consistent. Moreover, they have a crucial role from the ecological and environmental point of view. These two groups of areas stand in between the urbanized sectors of the valley floor and the mountain areas endowed with high landscape value. They can be considered as some sort of filters, since they are the spaces of the relationship between valley floor and mountains. As a matter of fact, the provincial plan seems to promote the idea that settlement expansion is more relevant and necessary than the preservation of high-environmental valued areas, despite their significant role. Nevertheless, what this context has experienced in the last 10 years can be expressed as a devolution of responsibilities about planning issues from the provincial level to the municipal one, as already experienced in other 
European contexts [5]. This sort of shift-to-local makes municipality a more powerful actor in urban planning. The municipalities can, for example, legitimately change the perimeters of the "agricultural areas with protection and conservation aims", in order to carry out the building expansion, undermining the high-environmental value of some portions of valley landscape.

\subsection{The geography of the transformation areas of municipal plans}

In this uncertain panorama connoting the provincial level, each municipality has been free to foresee its expansion, legitimately changing the perimeters the areas endowed with highenvironmental value. A varied set of municipal land-use forecast policies has been developed, in absence of meaningful forms of inter-municipal cooperation, Fig. 1. The research has analysed the various municipal planning tools to investigate the land-use forecast of each plan. Every transformation area was mapped and surveyed to specify functions, surfaces, volumes and number of future inhabitants. This survey found that the vast majority of the transformation areas regard medium-small size development projects (between 800 and $15,000 \mathrm{sqm})$. This widespread geography of small-medium transformation areas is a proof of a municipal political will which has expressed a local urban planning by forecasting small expansion interventions, without carrying on an attempt to create an overall large-scale expansion framework in Seriana Valley.

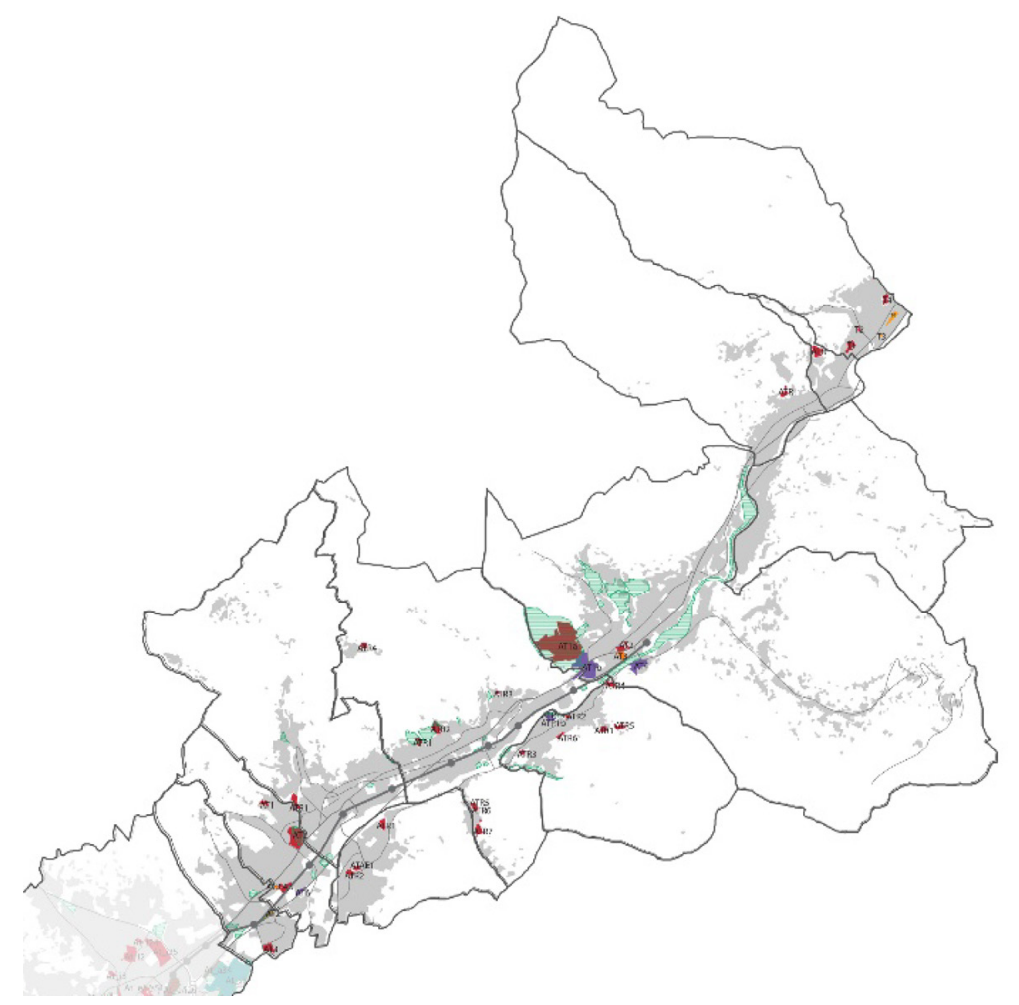

Figure 1: Current land-use forecast in Seriana valley. 


\section{THE REORGANIZATION OF LAND-USE FORECAST: WORKING BY SCENARIOS}

The aim of the inter-municipal reorganization of land-use forecast carried out by the research is to limit the dispersion of the valley urban settlements and to establish an overall coherency in the urban expansion of Seriana Valley municipalities. Moreover, the aim of this operation is to reduce the overall soil consumption and to establish an inter-municipal shared design framework aimed at concentrating the development rights in few strategic areas. To reach this purpose, three criteria have been identified according to which analysing the current land-use forecast. The criteria concern aspects dealing with environment (compatibility of the transformation areas with the preservation of ecological transversal corridors of the valley), accessibility (compatibility of the transformation areas with the analysis of generators and attractors of mobility) and coherence with higher level planning tools [4]. Through the intersection of these three criteria, the research brought to a table drafting through which the compatibility (or acceptability) of each transformation area to the criteria framework was established. Next to the presence of some "acceptable areas" with respect to the three criteria, we observe a quite varied panorama in which the land-use forecast present weaknesses depending on some transformation areas. The so-called "non-acceptable areas" are the ones which are not compatible with one or more criteria. Thus, it is proposed to move the development rights of these areas elsewhere, according to an overall inter-municipal reorganization of development rights. The planning tool to be used in this case is the "Territorial Transfer of Development Rights" (TDR) (in Italian "perequazione territoriale") which concerns the exchange of development rights between different municipalities [1, 2, 6].

\subsection{First scenario: high degree of cooperation between municipalities}

The first scenario envisages a broad political cooperation between the municipalities in Seriana Valley for designing a shared land-use forecast. In this case, it has been experimented the case according to which all municipalities in Seriana Valley could establish an agreement in the field of urban planning, aimed at reorganizing the development rights at inter-municipal level, as it happened recently in other Italian contexts [7-9]. The first step of the agreement is the retrieval of a transformation area where concentrating the development rights coming from the "non-acceptable transformation areas". It was chosen to concentrate the volumes in Albino, the most populous town in Seriana Valley; this municipality is placed in a central position with respect to the valley territory. Moreover, the choice of the landing area within Albino was done according to a variety of factors including the proximity of the area to the built environment, the coherency of the new volumes with the urban context conditions and the transport supply conditions in relation to the demand generated by the foreseen inhabitants to optimize the accessibility conditions in relation to existing public mobility network. The TDR has carried out by maintaining the original functions of the transformation areas. Therefore, the three receiving areas correspond to three distinct (predominant) functions: a residential area (with minor commercial), a tertiary area (with minor commercial) and an industrial area (with minor tertiary). Although this scenario represents from the political point of view a reasonable opportunity, is a remote possibility in this specific context, since it represents a political choice connoted by a high degree of collaboration between municipalities, while in the current Seriana Valley context we currently detect a lack of cooperation between municipalities in urban planning sphere. 


\subsection{Second scenario: low degree of cooperation between municipalities}

The second scenario explored the hypothesis according to which small groups of municipalities establish agreements for the reorganization of development rights at inter-municipal level. In this case, the level of cooperation between municipalities is lower than in the first case; it leads groups of two or three municipalities to work together for a common land-use forecast. The receiving municipalities were chosen thanks to the place-node status analysis, an assessment methodology, [10], aimed at quantifying the transportation functional value ("node status") and urban functional value ("place status") of the stations of the tram line "T1" Bergamo-Albino in Seriana Valley, fig. 2. This line is considered the most important and efficient public infrastructure of the Valley mobility. It was opened in 2009, exploiting the existing but disused tracks of the Seriana Valley railway. The place-node status analysis ranking methodology has been applied through the identification of $800 \mathrm{~m}$ buffer zones (the centres of the buffer zones are the tram line stations). For the calculation of place-status of each station, the following elements were taken into consideration: the population and activities around the stations in terms of inhabitants and uses, the number of residents, commuting workers and students, the degree of attractiveness of existing polarities in terms of the number of generated trips. For the calculation of the node-status of each station, the following elements were considered inside the buffer zones: the infrastructural facilities of the stations in terms of available inter-connections, the number of train trips per day, the number of bus trips per day, the number of interchange parking lots and the existing meters of cycle path. The place-node status analysis has identified a number of stations (Ranica, Pradalunga and Albino) for which the values of place status are comparatively lower than those of other stations. In order to balance the current situation and, therefore, to increase the values of place-status of those lacking municipalities, it was decided to transfer the development rights from the "not acceptable" transformation areas to those transformation areas located inside the buffer zones of the stations, which were ranking lowest in place-status analysis. Consequently, according to the new land-use forecasts, previously low-place status municipalities increased their ranking; as can be observed in the diagram, the corresponding points of Ranica, Pradalunga and Albino move their locations to the right.
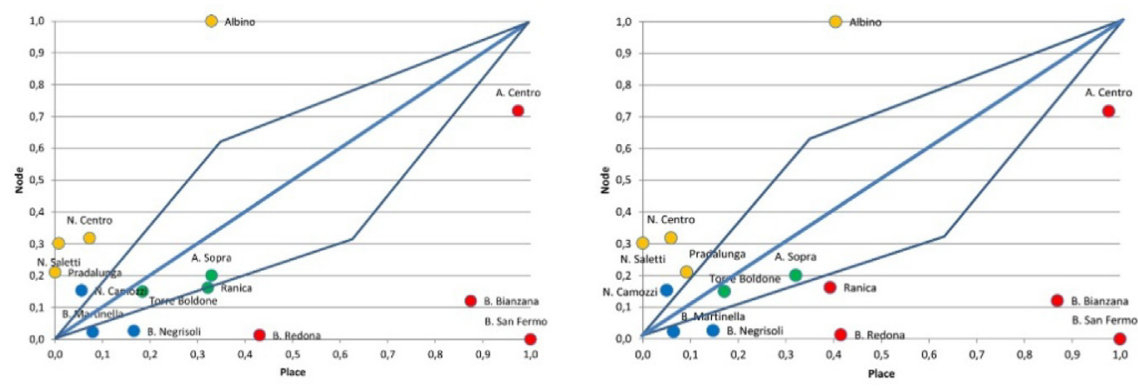

Figure 2: Diagrams of the place-node status analysis for the classification of tram-stations in Seriana valley, made considering $800 \mathrm{~m}$ buffer zones. On the left: the current situations; on the right: the situation considering the new land-use forecast. 


\subsection{Third scenario: lack of cooperation between municipalities}

In the third scenario of development rights' reorganization in Seriana Valley, it has been explored the hypothesis that the municipalities decide not to cooperate in the field of landuse forecast, and they produce by themselves their expansion framework. This assumption represents the natural evolution of the political-administrative current reality: a context in which each municipality has been developing independently and with its own resources the municipal plan, identifying autonomously the areas where to build within its municipal boundaries. Thus, the development rights corresponding to non-acceptable transformation areas are transferred in other areas of transformation within the same municipality. Only in the case of Torre Boldone, a small town located in the southwest portion of the Valley floor, the two foreseen transformation areas (one residential and the other one commercial/tertiary) are both in contrast to the previously identified criteria; thus development rights are transferred in the neighbouring municipality, Ranica. In this scenario, all municipalities (except Torre Boldone) maintain the share of building rights foreseen by the municipal plans unchanged.

\section{INTER-MUNICIPAL REORGANIZATION OF LAND-USE FORECAST}

The first scenario is the most likely if we do want to think about hypotheses of reorganization of development rights at inter-municipal level $[1,2,6]$. It was decided to think in detail about this option since the ten municipalities of Seriana Valley represent an optimal ambit for an inter-municipal redefinition of land-use forecasts which would be effective and that would lead to a real reduction of soil consumption. This reasoning is meant to describe a drawing of inter-municipal cooperation in the field of urban planning and to carry out hypotheses of TDR among municipalities. It must be specified that the three landing transformation areas located in Albino, whose development rights are distinguished into residential, tertiary and industrial, have been identified on the basis of compatibility regarding the three criteria previously identified. Firstly, the landing areas do not contrast with the environmental performances of transversal ecological corridors; then, they are in favourable positions with respect to the system of generators and attractors of mobility; last but not least, they are coherent with the requirements of the provincial plan of Bergamo, [4].

\subsection{Estimating the missing amounts of services}

Taking into account quantitative aspects, we have examined what could happen in the landing residential area. At this purpose, we chose the area AT2 from the Albino Municipal Plan [11]; residential volumes coming from the inter-municipal reorganization of land-use forecast will be concentrated in this area. The goal is to estimate the amount of services required by the foreseen residents who will settle down in AT2. In AT2, the Albino plan currently foresees 214 new residents. According to the reorganization of development rights, further 2,528 inhabitants are going to be settled down in AT2. This large amount of new inhabitants corresponds to all the residents foreseen by the transformation areas taking off from the other municipalities of the valley. For what concerns the foreseen internal floor area (in Italian "superficie lorda di pavimento"), this amounts to $137,120 \mathrm{sqm}$, to be distributed on a portion of land equal to 19,454 sqm. The new inhabitants who will settle down in AT2 will bring the inhabitants of the City of Albino to grow from the current 18,218 to the expected 20,960 inhabitants. The current estimation of services is $505,358 \mathrm{sqm}$ for the whole municipality; 
this amount is able to guarantee 28 sqm of services per inhabitant. It's relevant to underline that this service ratio is higher than the minimum provided by the Regional Law n.12/2005 (18 sqm per inhabitant). It was decided in this case to maintain the current service ratio ( $28 \mathrm{sqm} /$ inhab.) to guarantee to the new residents the same amount of services that the Albino residents have right now. In this respect, it is estimated that other 76,787 sqm of services must be realized to maintain unchanged current service ratio.

\subsection{The impact of the new settlement on the urban surroundings}

The first step to understand the impact of the new settlement on the urban surroundings is a functional analysis, aimed at analysing which features characterize the close urban environment, in terms of practices and uses of urban space. The landing transformation area AT2 is located in a filter zone between the historical settlement of Albino, characterized by historical buildings of 3-4 storeys, and a more recent industrial district close to the Serio river banks. The concentration of development rights in AT2 takes place according to two possible cases, fig. 3. In the first case, the building surface (Sf) is equal to the plot area (St). Therefore, the receiving internal floor area (equivalent to $137,000 \mathrm{sqm}$ ) has to be distributed in a portion of $19,454 \mathrm{sqm}$. The resulting building is made of 7 floors, three more than the average height of the urban surroundings. The second case considers that the building surface Sf, equal to $13,560 \mathrm{sqm}$, is less than the plot area St; in this sense the aim is to take into account the Municipal Plan prescriptions about AT2 concerning the preservation of an historical building and a green area located within the AT2. By considering these guidelines, the resulting urban ensemble is highly discordant from the surroundings; the foreseen building will be made of
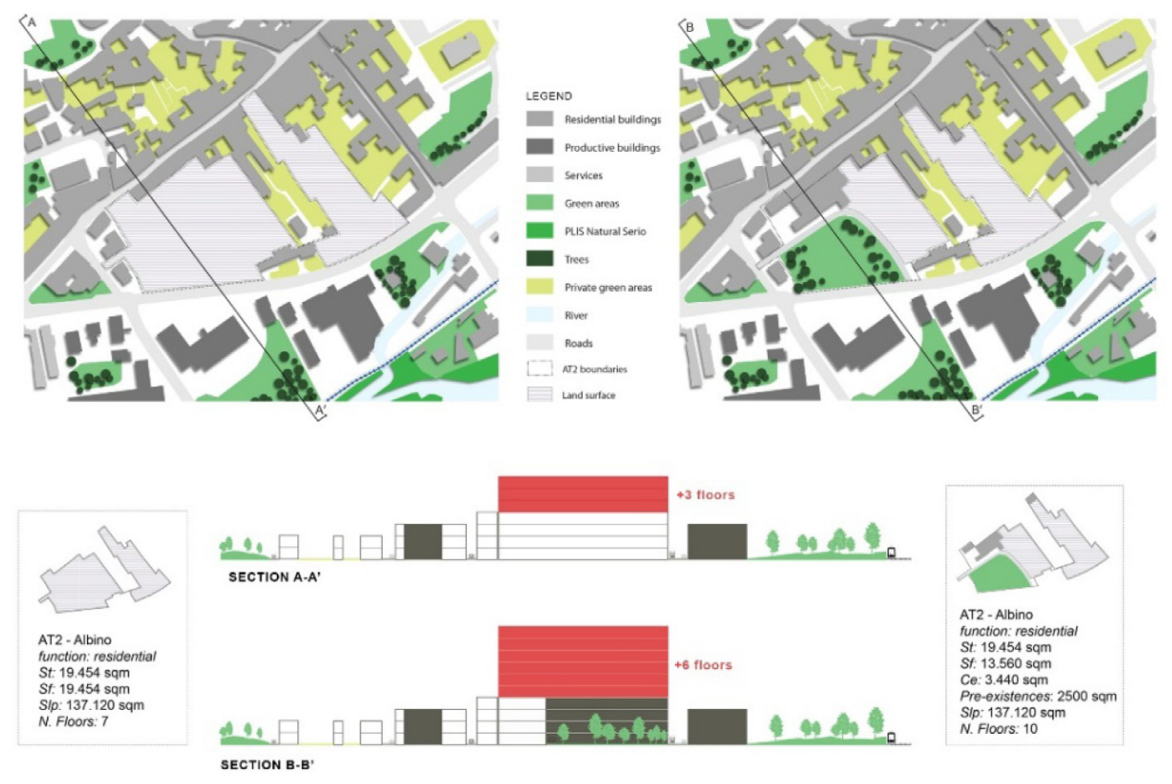

Figure 3: Two cases of arrangement of the volumes in AT2 transformation area considering $\mathrm{St}=\mathrm{Sf}$ (on the left) and $\mathrm{St}>\mathrm{Sf}$ (on the right). 
10 floors above ground, 6 of which beyond the maximum height of the surrounding buildings. Although none of these cases does integrate with the surrounding urban landscape, such reasoning is useful to understand the urban repercussions arising from the concentration of residential building rights in one area, in this case the AT2 located in Albino. It follows that the most desirable political scenario at inter-municipal level, namely a political agreement between all the municipalities of Seriana Valley for the reorganization of development rights and their concentration in one area, clashes with the need to choose an appropriate landing area that could get the volumes moderating the impact on close surroundings, and avoiding discrepancies at the level of urban landscape.

\subsection{Estimation of the monetary compensations for each municipality}

The amount of sqm and inhabitants foreseen in AT2 in Albino, besides producing a strong impact on urban surroundings, requires the creation of a so-called "Compensation Fund", a tool whose role is to collect and distribute the monetary resources coming from the actors involved in the process; it is finalized to estimate the financial compensation due to each Municipality yielding development rights. The formula chosen to estimate the compensation to be allocated to each municipality has been taken from one of the most recent and innovative inter-municipal plans (PATI) elaborated in Italy. In the PATI of Camposampierese [12], carried out by a group of eleven municipalities in the province of Padova in the north of Italy, the regulations' document ("Norme tecniche di attuazione") makes use of the TDR tool for the inter-municipal land-use forecast. As stated in the plan, the TDR ("perequazione territoriale") is defined as the "process that carries on the rebalance and the equitable redistribution between the involved municipalities of the monetary benefits and costs resulting from the settlement concentration defined by inter-municipal planning decisions". The formula for the redistribution of monetary benefits coming from the TDR application is the following:

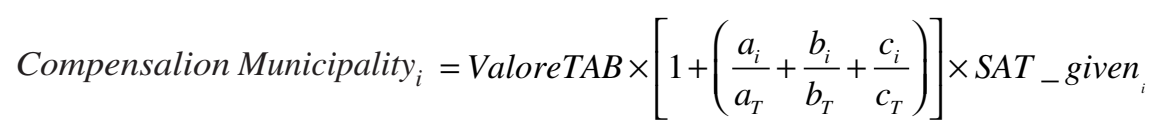

$\begin{aligned} \text { Compensation Municipality } & =\begin{array}{l}\text { Compensalion due to every municipality giving SAT } \\ \text { (surface of transfomation area) }\end{array} \\ & =\text { SAT given by } i \text { Municipality } \\ a_{i} & a_{1}+a_{2}+a_{3}+a_{4}+a_{5} \\ a_{T} & =\text { Inhabitants of } i \text { Municipality } \\ b_{i} & =b_{1}+b_{2}+b_{3}+b_{4}+b_{5} \\ b_{T} & = \\ c_{i} & \text { surface of the } i \text { Municipality } \\ c_{T} & =c_{1}+c_{2}+c_{3}+c_{4}+c_{5} \\ \text { ValoreTAB } & =\text { avarage market value }\end{aligned}$

The formula produces a proportional distribution of benefits arising from the new settlement to the Municipalities participating to the inter-municipal reorganization of building rights. Therefore the monetary values take into account not only the surface of the taking-off transformations areas, but also the number of inhabitants and the surface of the Municipalities. The so-called "ValoreTAB" indicates the current status of the land of the taking-off transformation areas. This was extracted from the document reporting the average values of agricultural land of 2014 drawn up by the Province of Bergamo. Therefore, depending on the 
status of the land (arable land, lawn, woods, etc.) of the areas, a given market value of the land influences the compensation due to each municipality.

\subsection{Benefit and cost factors resulting from the new land-use forecast}

After having established the system to be used for distributing the monetary benefits arising from the inter-municipal reorganization of development rights, the following step provides the identification of the resources constituting the benefit factors. The development of the AT2 transformation area will produce primarily a share of planning obligations which are estimated around 49 million euro, obtained by multiplying the total internal surface for 200 Euros (average market value). Since every municipality has given varying amounts of buildable surface, these benefits must be redistributed proportionately among all the municipalities on the basis of the percentages obtained previously. In addition to the planning obligations, also the taxes the new residents will have to pay a source of revenue. The research has therefore referred to TASI (municipal tax on "indivisible" services) and TARI (municipal waste tax). Considering their national average values of 2014 (156 euros per family for the TASI and 284 euros per family for the TARI), it is estimated that the 2,084 foreseen residents, which will go to settle down in AT2, will produce revenues amounting to 305,653 euros. This share of monetary benefits will be destined to Albino Municipality since this money will be used to balance the cost factors referring to the new transformation area: the most important shares of these costs relate to the adjustment of existing infrastructure, the public services' improvement (see paragraph 4.1) and the environmental rehabilitation of the neighbourhood with reference to new settlement expected impacts.

\section{CONCLUSIONS}

The three scenarios have been able to describe a range of possibilities that municipalities, especially small ones, can go through in order to develop their land-use forecast. The first scenario describes the most viable hypothesis concerning an effective and efficient intermunicipal reorganization of development rights. In this case, a form of political agreement between the ten municipalities of Seriana Valley allows to foresee new residential and industrial areas at inter-municipal level; the suggested tool is the "Compensation Fund", which can collect, manage and distribute the resulting cost and benefit raised by the new development. Moreover, a crucial phase of the process is the estimation of the impacts produced by the high concentration of development rights in the landing transformation areas, and by the population weight of the new settlements. Indeed new inhabitants will produce a new demand for services and public transport which must be taken into consideration. The second scenario has expressed a political agreement between small groups of two / three municipalities for an inter-municipal planning of land-use forecast. As in the first case, a form of compensation will be necessary to distribute among the municipalities the cost and benefit factors resulting from the new development areas. An assessment of the amount of services required by the foreseen inhabitants should be made to ensure that new inhabitants will have sufficient public facilities and infrastructures to guarantee fair life conditions. The third scenario, denoting a lack of cooperation between the municipalities for the land-use forecast, is the more likely case considering the current forms of localism and the absence of cooperation between Seriana Valley municipalities in urban planning sphere. At the same time, it represents the least desirable case, because of the current high soil consumption values and the weakened real estate conditions characterizing the Seriana Valley context. The 
case-studies chosen for the reorganization of the development rights at inter-municipal level draw a panorama of methods and tools municipalities can chose to reach a more sustainable vision of urban development. The scenario making process [13], even if sometimes evidently visionary and unattainable, can offer a useful answer to the current reality of dispersed and incoherent geography of the land-use forecast in Seriana valley. Nevertheless working by scenarios aims at producing and experimenting innovative solutions which could orient local urban planning towards alternative directions of development.

\section{REFERENCES}

[1] Adobati, F. \& Ferri, V., Perequazione territoriale. Tavoli di concertazione e misure di compensazione. Commercio e politiche territoriali: quattro temi emergenti, eds. F. Adobati, A. Oliveri \& L. Tamini, University Press: Bergamo, pp. 15-19, 2005.

[2] Gibelli, M.C., Extended transfer of development rights in Urban Planning: a singularity within the international context. Diritti edificatori e governo del territorio: verso una perequazione urbanistica estesa?, s.i. of Scienze Regionali, eds. R. Camagni, E. Micelli \& S. Moroni, 13(2), pp. 45-58, 2014.

[3] Clément, G., Manifesto del Terzo Paesaggio, Quodlibet: Macerata, 2005.

[4] Piano Territoriale di Coordinamento Provinciale di Bergamo, Province of Bergamo (approved by the Board Resolution n. 14 of April 22, 2004).

[5] Allmendinger, P. \& Haughton, G., Moving on - from spatial planning to localism and beyond. Town \& Country Planning, pp. 184-187, 2011.

[6] Micelli, E., La gestione dei piani urbanistici. Perequazione, accordi, incentivi, Marsilio Editore: Venice, 2011.

[7] Balducci, A., Fedeli, V., Manfredini, F. \& Pucci, P., I Territori della produzione. Riorganizzare gli spazi della produzione in provincia di Vicenza, Alinea Editrice: Florence, 2006.

[8] Bruzzo, A., Perequazione territoriale e compensazione finanziaria. Le opportunità dell'associazionismo a livello sovracomunale: il caso della Regione Emilia Romagna e della provincia di Bologna. Commercio e politiche territoriali: quattro temi emergenti, eds. F. Adobati, A. Oliveri \& L. Tamini, University Press: Bergamo, pp. 37-46, 2005.

[9] Carbonara, S. \& Torre, C., Urbanistica e perequazione: dai principi all'attuazione. Pratiche di compensazione e di valutazione nei piani, Franco Angeli: Milano, 2008.

[10] Bertolini, L., Nodes and places: complexities of railway station redevelopment. European Planning Studies, 4, pp. 331-346, 1996. http://dx.doi.org/10.1080/09654319608720349

[11] Piano di Governo del Territorio (PGT) di Albino (approved by Municipal Council on July 22, 2008).

[12] Piano di Assetto del Territorio Intercomunale (PATI) del Camposampierese (approved by the Service Conference on April 11, 2014).

[13] Viganò, P., I territori dell'urbanistica. Il progetto come produttore di conoscenza, Officina: Rome, 2010. 